\title{
Table of national and international legislation
}

\section{EUROPEAN PATENT CONVENTION}

Art.52(1) 197

Art.52(1)(c) 197

Art.52(4) 1973

Art.53(c) 1,41

\section{UNITED STATES}

Clinical Laboratories Improvement Act 40,42

Federal Food, Drug and Cosmetic Act (FD\&C) ................... 36, 40, 42

Genomic Research and Accessibility Act 2007

Genomic Research and Diagnostic Accessibility Act 2002

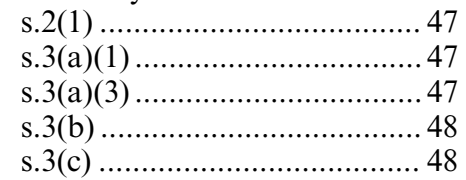

Genomic Science and Technology Innovation Act 2002 .. 46

Medical Procedures and Affordability Act 1995 $2,187,188$

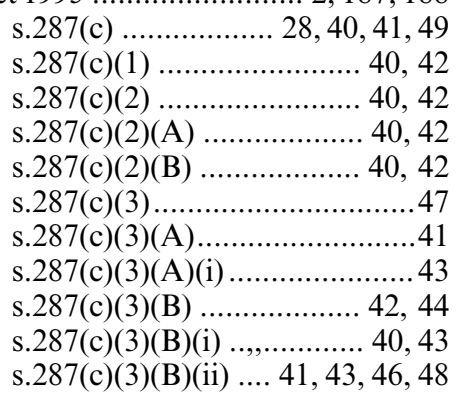

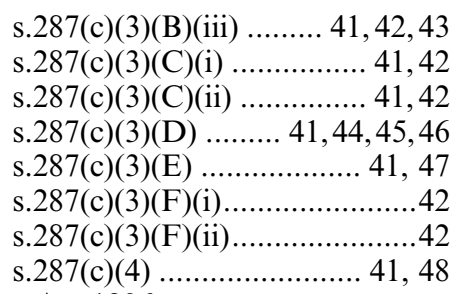

Patents Act 1836

s.6. .7

Patents Act Title 35 U.S.C. .............. 13 s. 100 $87,88,96$ s.100(b) .......... 56, 79, 82, 83, 96 s. $101 \ldots . .1,3,4,5,8,15,24,27,49$, $50,51,52,54,55,57,58,59$, $60,61,62,63,64,65,66,68$, $69,70,71,72,73,74,75,76$, $77,78,79,80,81,82,84,85$, $86,87,88,89,91,92,94,95$, $96,97,98,99,100,101,102$, 103, 104, 105, 106, 107, 108, $109,112,113,114,115,119$, $120,122,125,126,131,132$, $133,134,136,137,138,140$, $141,142,143,146,147,152$, $153,158,160,162,164,168$, $170,171,174,175,176,178$, $180,181,182,183,184,185$, 186, 187, 192, 193, 194, 195, 197, 198, 199, 200, 201 s.102 ....... 57, 59, 60, 62, 64, 69, $74,75,79,102,105,106$, $107,109,139,160,168$ s.102(g) .......................... 115 s. 103 .... 57, 59, 60, 62, 64, 69, 79, $102,105,106,107,109,168$ s.103(b) ..............................42 s.112 .... 79, 89, 98, 106, 107, 109, 
s.271(a)

s.271(b)

s.273(b)(1)

s.287(c) s.287(c)(2)

s.287(c)(4)

Public Health Service Act ......... 36, 40, 